\title{
Fuzzy decision analysis for project scope change management
}

\author{
Farshad Shirazi $^{\mathrm{a}}$, Hamed Kazemipoor ${ }^{\mathrm{b}^{*}}$ and Reza Tavakkoli-Moghaddam
}

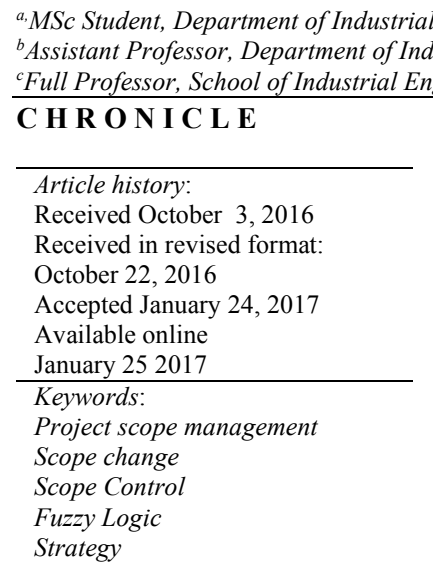

\section{Introduction}

Project is a temporary attempt carried out to create a unique product, service, or result (PMI, 2013). Projects are the central activity in many companies (Alsudiri et al., 2013; Cooke-Davies, 2002). The right execution of the project management can add great value to an organization. However, some organizations have gained little value from the project management because they have not applied the project management in a proper way (De Reyck et al., 2005; Ming \& Meng, 2009). One of the major problems in developing countries is that the use of resources is not managed well in the projects. The result is time and cost overrun in the projects and perhaps the projects are terminated for these overruns. There are many standards for project management in addition to time and cost, which must be considered. The importance of project management is described in the PMBOK and other standards (PMI, 2013). But still with all the different standards, the risk of failure in projects is very high (Meredith \& Mantel, 2011; Sun \& Meng, 2009). For the first time in the 50s, the first step of project

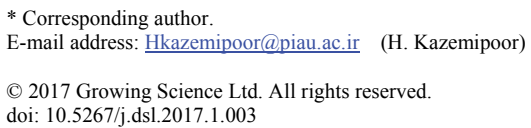


management was established in the NASA that considered all the procedures and methods of project management (Kerzner, 2013). Later, more studies took place on project management that developed different standards like the PMBOK, PRINCE2 and the APM (Thomas \& Mengel, 2008).

There are different standards for project management such as the PMBOK, PRINCE 2 and the APM. One of the reasons that a project may fail is scope creep. Scope creep is the uncontrolled changes in a project. Ming and Meng (2009) developed two categorizations for the reasons and their results of changes on a project. They presented and combined existing literature on project change reasons and their results, then developed two classifications for change reasons and change results; and finally illustrated how the classifications can be used during the project change management process. Crawford and Nahmias (2010) and Crawford et al. (2006) studied the required competencies to prevent scope creep in projects. They reported on the study carried out to look at the differences in approach and practice of project, program and change managers as a source for verifying the capabilities required to successfully manage change initiatives. Stummer and Zuchi (2010) analyzed different change roles and project and program roles in the literature and identified shortcomings, presented the change roles developed in the case study, reflected the necessity for an explicit definition and differentiation of change, program and project roles for the fulfillment of a transformation, and analyzed the advantages as well as disadvantages of the application of multi-role assignments in changes. Lehtonen and Martinsuo (2009) discussed the arrangement of change programs with their organization by considering two case studies. They extended a situated and dynamic structure on program-parent combination. As it can be noticed from the studies, there has been few studies on scope creep. With considering less research on scope creep and based on the PMBOK a model to prevent and manage scope creep in projects is provided (Meskendahl, 2010; Shi, 2011; Eriksson, 2013). Yet, the project's success means more than just meeting triple constraints, i.e. time, cost and scope. This highlights other success dimensions such as the business outcomes, which can be achieved through a proper alignment between the project management process and the organizational strategy (Patanakul \& Shenhar, 2012; Shenhar et al., 2000; Morris \& Jamieson, 2005). By considering this concept, in this paper we discuss scope change and managing scope. Fuzzy analytical hierarchy process (AHP) is used in selecting the best strategy to manage scope change in projects. To handle humans' subjective judgments under complex environments, great studies have been executed to overcome the problem where the traditional Saaty's AHP (Saaty, 1990) is facing a very unbalanced scale of estimations (Fan et al., 1998; Hauc \& Kovač, 2000). Yeh and Deng (1997) proposed a process for solving general fuzzy multi-criteria decision making problem involving fuzzy data expressed by means of linguistic terms. For handling human's subjective judgments, Mon and Lin (1994) proposed fuzzy AHP based on entropy weight to evaluate the weapon systems.

This paper organized as follow. In the second section the definitions of scope, scope change and scope creep are described. In the third section, with the information gained from the previous section a checklist is produced to find the main causes of scope creep and then we recognize the main causes of scope creep for power plant projects. Finally, in the fourth section, we propose a model to manage scope change.

\section{Definition of scope, scope change and scope creep}

In this section of the paper by the base on the PMBOK, the concept of project scope, scope change and scope creep has been presented and a check list has been developed to assess the main causes of scope creep in the projects (PMI, 2013).

\subsection{Scope}

The PMBOK considers scope as one of the most important areas in a project that can influence the project success. Scope has two categories as mentioned in the Table 1: 
Table 1

Projects scope

\begin{tabular}{|c|c|c|}
\hline Scope & Project scope & Product scope ( spec) \\
\hline Definition & $\begin{array}{l}\text { The work that must be done in order to } \\
\text { deliver a product (meetings, reports. } \\
\text { Analysis and...) }\end{array}$ & $\begin{array}{l}\text { Features and function that are to be } \\
\text { included in a product }\end{array}$ \\
\hline Completion is Measured against & Project Management Plan (PMP) & The product requirements \\
\hline Approved by & Project manager & Customer \\
\hline
\end{tabular}

Scope management is the process to ensure that the project contains only the work required to successfully complete the project intentions stated in the project charter. In other words, project scope management is to identify and control what should be and what should not be in a project (Thomas \& Mengel, 2008). In fact, It should be noticed that scope management includes both product and project scope.

\subsection{Scope creep}

One of the specifications of a project is that it is progressively elaborated; it means that with proceeding in project steps, the detail information of the project will be defined. For this reason, during the project, many positive or negative changes may occur. Changes in a project cannot be completely prevented so the changes should be controlled. Control scope is concerned with monitoring the status of the project and product scope, determining whether or not a scope change has occurred, managing the actual changes that have been integrated with other project areas including schedule, cost, quality, risk, insure that the changes are agreed and influencing the factors that can cause the scope changes. Uncontrolled changes are often referred to as project scope creep (Kerzner, 2013). The definition of scope change and scope creep shall be discussed as follow:

\section{Scope Change}

Scope change is any change to the project's scope. The scope change cause can be of an external event, an error in defining the scope of the product, an error in defining the scope of the project, or a valueadding change. Scope change always requires an adjustment to the project baselines. It should be noticed that scope change can include preventive or corrective actions or defect repairs (Ming \& Meng, 2009).

\section{Scope Creep}

Scope creep is adding features and functionality to the scope without addressing the effects of it on the project management plan (PMP), project baselines or without customer agreement (Lehtonen \& Martinsuo, 2009).

\section{Main factors of scope creep}

In this section, with use of the Delphi technique (Rowe \& Wright, 1999), the causes of scope creep are collected; a questionnaire list is developed on the base of the PMBOK and was sent to 25 experts of 5 projects in; responses were compiled and then the results were back to them until consensus was reached. By the end with the use of an affinity diagram the scope creep causes were sorted in similar groups (Stummer \& Zuchi, 2010). The questionnaire is presented in Table 2 and based on PMBOK it has been divided to 3 categories; inputs to scope control process, tools and techniques of scope control process and the out puts of scope control process: 
Table 2

Questionnaire

\begin{tabular}{|c|c|}
\hline $\begin{array}{l}\text { Scope control } \\
\text { process }\end{array}$ & Questions \\
\hline $\begin{array}{l}\text { Inputs to scope } \\
\text { control process }\end{array}$ & $\begin{array}{l}\text { Requirement management plan } \\
\circ \quad \text { Is there a process to collect the project requirements? } \\
\circ \text { Is there a process to rank the project requirements? } \\
\circ \text { Is there a traceability structure to follow the requirements? } \\
\circ \text { Is there a plan to manage the configuration? } \\
\text { Project scope statement } \\
\circ \text { Are the assumptions documented? } \\
\circ \text { Are the constraints documented? } \\
\circ \text { Have the business needs been defined? } \\
\circ \text { Does the client know exactly what they need? } \\
\circ \text { Is the client involved in the first phases of the project life cycle? } \\
\circ \text { Is there a correct definition of the project terms? } \\
\circ \text { Is the project scope statement used as the base for future project decisions? } \\
\text { Work break down structure (WBS) } \\
\circ \text { Is the work break down structure used to manage the project life cycle? } \\
\circ \quad \text { Is a work break down structure dictionary used to manage the work? } \\
\text { Change management plan } \\
\circ \text { Is the change management system procedure prepared by a qualified team? } \\
\circ \text { Are the project team members involved in the preparation of the change management plan? } \\
\circ \text { Is the change management plan checked by a third party? } \\
\text { Communication } \\
\circ \text { Is there a communication management plan for the project? } \\
\circ \text { Is there a procedure to prepare the project reports? }\end{array}$ \\
\hline $\begin{array}{l}\text { Tools and } \\
\text { techniques of scope } \\
\text { control process }\end{array}$ & $\begin{array}{l}\text { Is the change control system used in the performing organization? } \\
\text { Is the power and responsibilities of the change control board used? } \\
\circ \text { Is it determined that a change is needed? } \\
\circ \text { Are the change request documented? } \\
\circ \text { Are the changes integrated with the other knowledge } r \text { areas } \\
\circ \text { Is information informed to the stakeholders on time? } \\
\text { Is the configuration management plan used to integrate change across project areas? }\end{array}$ \\
\hline $\begin{array}{l}\text { Out puts of scope } \\
\text { control process }\end{array}$ & $\begin{array}{l}\text { Is the PMP Updated on time? } \\
\text { Are the changes and the revised PMP informed to the stakeholders on time? } \\
\text { Are the lessons learned documented? }\end{array}$ \\
\hline
\end{tabular}

By the use of the checklist on 5 projects, the 9 main reasons of scope creep in power plant projects have been identified as Poor change control, Poor documentation, Poor information transformation, External changes, Internal changes, Unmanaged expectations, Not using scope statement for future decisions, Not using the correct technique for work break down structure (WBS) and Not having a scope management plan. By the use of the Paroto rule and an analysis on the causes of scope creep, the first four main causes that were about $70 \%$ of the causes of scope creep in the projects have been identified. With the help of the opinions of mentors, documents, previous projects, articles and books, the main causes of scope creep has been collected in Table 3:

\section{Table 3}

Main causes of scope creep

\begin{tabular}{|c|c|c|}
\hline Main scope creep cause categories & Discretion & Scope creep cause \\
\hline Poor documentation & $\begin{array}{l}\text { Bad definition of scope and the } \\
\text { misconstruction of the project's } \\
\text { scope and contract }\end{array}$ & $\begin{array}{l}\text { Defining the scope by inexperienced experts. } \\
\text { Misconstruction of the business needs. } \\
\text { Bad realization of client's needs in defining the scope. } \\
\text { Unrealistic project goals. } \\
\text { Variety in the size and the detail of scope statement and not } \\
\text { checking it by a third party. } \\
\text { Lack of clarity about system boundaries }\end{array}$ \\
\hline Poor change control & $\begin{array}{l}\text { The duty of the project team } \\
\text { based on the assumptions }\end{array}$ & $\begin{array}{l}\text { Define the procedures by inexperienced experts. } \\
\text { Not involving the project team for defining the procedures. } \\
\text { Not checking the procedures by a third party. }\end{array}$ \\
\hline Poor information transformation & $\begin{array}{c}\text { Not understanding of the } \\
\text { project goals and scope } \\
\text { baseline and the situation of the } \\
\text { project }\end{array}$ & $\begin{array}{l}\text { Lack of configuration management plan. } \\
\text { Lack of communication. }\end{array}$ \\
\hline External changes & $\begin{array}{l}\text { Change of law, technology, } \\
\text { weather and economical } \\
\text { situation }\end{array}$ & Not having risk management. \\
\hline
\end{tabular}




\section{A decision analysis model for change option selection}

As it can be understood from the table, it is obvious that scope creep does not occur in the first phases of the project and it usually occurs in the next phases; when the project team has more information on the project, the problems and the solutions. It is almost impossible to prevent changes in scope; that is why a scope change management system should be established for the project.

Project strategy shows direction of the project to achieve successfully the project objectives in its environment (Artto \& Martinsuo, 2008). In other words project strategy is the project perspective, position, and guidelines for what to do and how to do it, to accomplish the best competitive advantage and the best value from the project. Porter (1980) claimed that organizations can achieve a sustainable competitive advantage, through reinforcing their efforts on one of the cost leadership or differentiation strategies. According to Porter's generic strategies, when an organization chooses only one strategy it provides the organization with the ability to achieve competitive advantages and outperform their competitors (Srivannaboon \& Milosevic, 2006). In this paper, based on the Porter's business strategy topology and the framework by Milosevic and Sabin Srivannaboon (2006), we used 3 strategies defined as bellow:

\section{- Cost leadership:}

Organizations pursuing a cost leadership strategy seek to gain competitive advantage by being the lowest cost producers in the industry. In a project driven by this strategy, team aim is on getting the job executed by concentrating cost reduction goals. The project process of cost leadership strategy is highly standardized and built on templates 0. Schedule is important because it helps the cost leadership company save money if the project finishes on time. Measure of project success is calculated by cost-saving, or net present value (NPV).

\section{- Differentiation:}

Organizations following a differentiation strategy try to find a position for themselves in the market with a different identity that satisfies the desires of their customers. This differentiation allows the organization to charge a premium price (Wheelen \& David, 2002).

\section{- Best-cost:}

Under certain conditions, many researchers claim that a combination of strategies may be the best way of creating a supportable competitive advantage. In particular, organizations may more effectively create a sustainable competitive advantage when they combine cost leadership and differentiation, to provide low-cost products and address customer values such as fast time-tomarket, superior product quality and innovative features (Wheelen \& David, 2002). The key is to find the level of the differentiation at a reasonable cost.

The triple-constraint is a structure for project managers to assess and balance these competing demands. Project managers are expected to manage time, cost, scope and quality. Projects that are accomplished within these constraints may not necessarily noted to be successful by key stakeholders (Duggal, 2010). Therefor, the project manager in addition to consider the triple constraint of the project has to reflect and make project decisions based on the accomplishment of the business outcome; Cost has to optimize business benefits like ROI, NPV, time has to optimize benefits of faster or time-to-market, scope has to reflect innovative features, and quality has to be balanced with superior customer quality. Project Strategy Translates the desired competitive advantage into guidelines for project participants based on the triple constraint of time, cost and scope/quality as showed in the Fig. 1. 


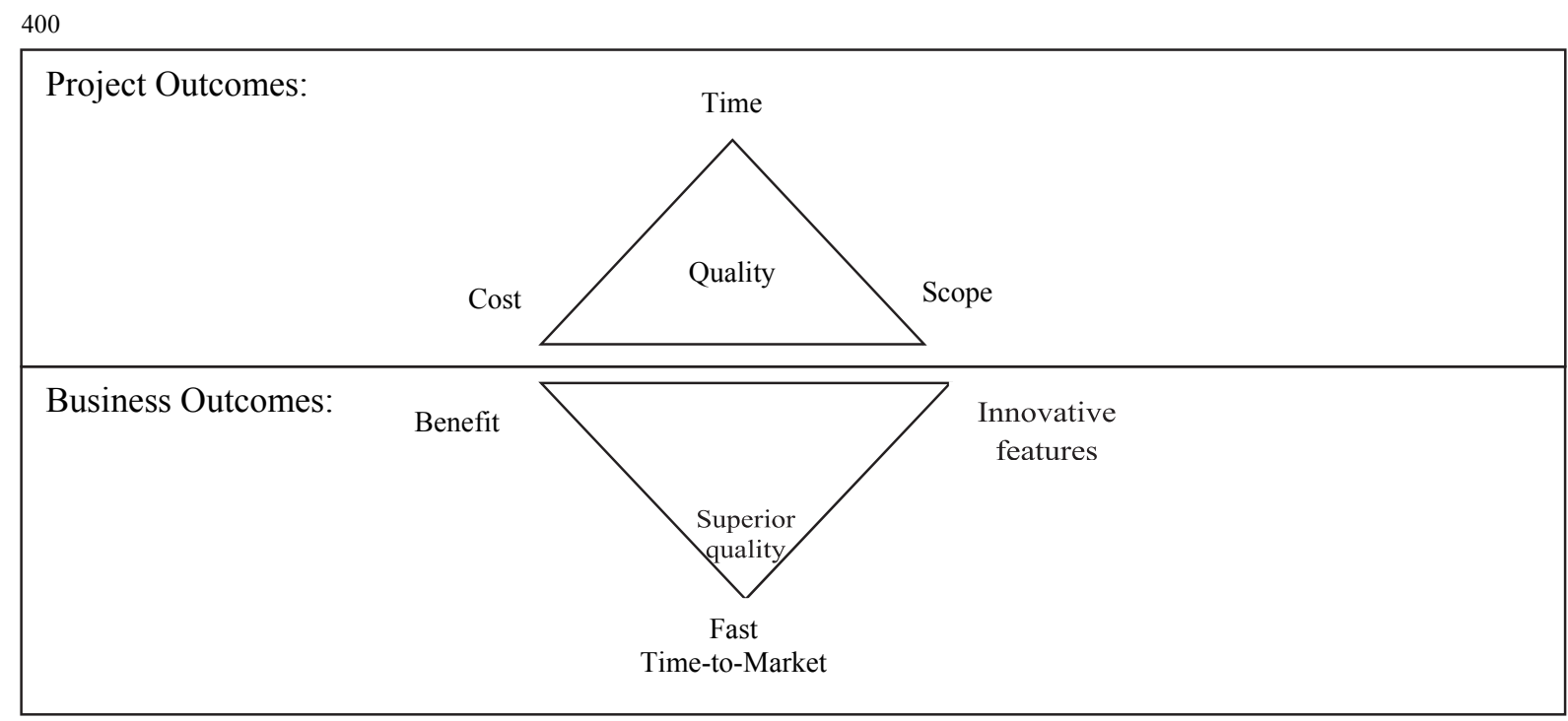

Fig. 1. Linking project outcomes to business outcomes

A presented in Fig. 1 differentiation in project should be based on fast time-to-market, superior quality and service, innovative features; therefore three types of differentiation can be mentioned in projects.

\section{Hierarchy Structure}

Analytic Hierarchy Process (AHP) technique is used in complex decision-making problems. In this study, a hierarchy structure is used based on Table 1 with four alternatives and two criteria for the best project strategy selection. Due to the ambiguity of human judgment and network fluctuating condition, fuzzy logic as well as entropy weighting methods are the most suitable candidates to originate the priority among the alternatives. The hierarchy structure is described in Fig. 2.

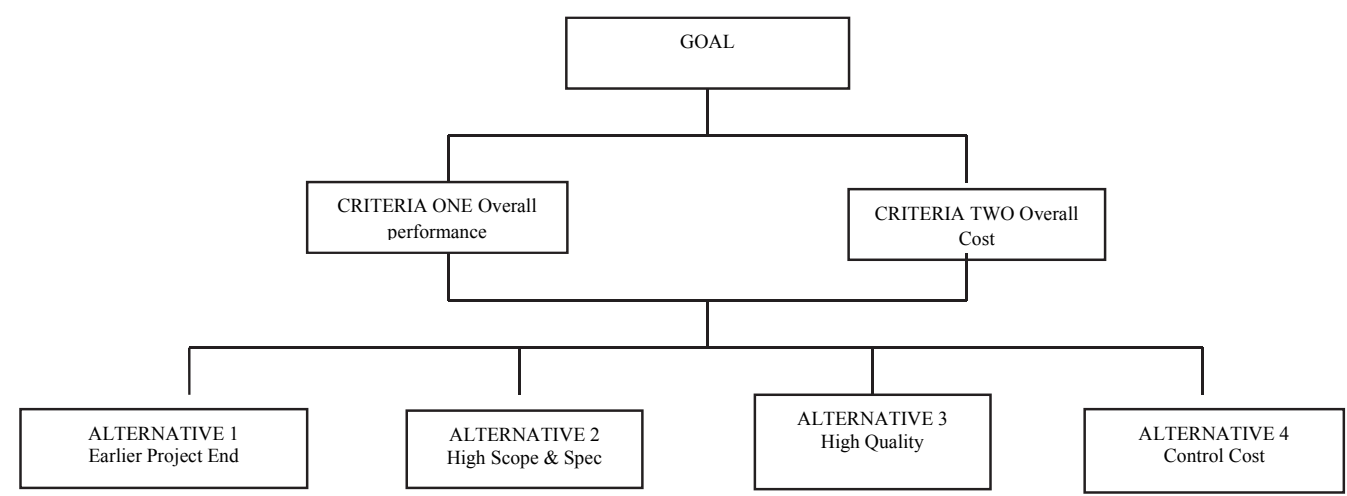

Fig. 2. Hierarchy Structure Model of Strategy Alternatives

\section{Shannon Entropy - Entropy Weight Derivation}

Shannon entropy is initially derived from thermodynamics studies. Shannon entropy provides a measure of information and the information achieved from an event is inversely linked to its probability of occurrences. Shannon defined the n-state entropy function with base-2 logarithm as:

$$
H=-\sum_{i=1}^{n} p_{i} \log \left(p_{i}\right)
$$

where $\mathrm{p}_{\mathrm{i}}$ is the frequency and the entropy weight is followed as: 
The $\mathrm{V}, n \times n$ matrix is a crisp judgement matrix:

$$
V=\left[\begin{array}{cccc}
v_{11} & v_{12} & \ldots & v_{1 n} \\
v_{21} & v_{22} & \ldots & v_{2 n} \\
& & & \\
v_{n 1} & v_{n 2} & \ldots & v_{n n}
\end{array}\right] .
$$

The normalized matrix is showed as follows:

$$
\left[\begin{array}{cccc}
\frac{v_{11}}{r_{1}} & \frac{v_{12}}{r_{1}} & \ldots & \frac{v_{1 k}}{r_{1}} \\
\frac{v_{21}}{r_{2}} & \frac{v_{22}}{r_{2}} & \ldots & \frac{v_{2 k}}{r_{2}} \\
\frac{v_{k 1}}{r_{k}} & \frac{v_{k 2}}{r_{k}} & \ldots & \frac{v_{k k}}{r_{k}}
\end{array}\right]=\left[\begin{array}{llll}
f_{11} & f_{12} & \ldots & f_{1 k} \\
f_{21} & f_{22} & \ldots & f_{2 k} \\
f_{k 1} & f_{k 2} & \ldots & f_{k k}
\end{array}\right],
$$

where $R i$, with $i=1,2,3, \ldots, k$, is the sum of the $\mathrm{i}$-th row and $f_{i j}$ is the relative frequency $\mathrm{f}_{i j}=\mathrm{v}_{\mathrm{ij}} / r_{i}$.

From Eq. (1), the entropy is defined as below:

$$
\begin{aligned}
& H_{1}=-\sum_{j=1}^{k} p_{1 j} \log _{2}\left(p_{1 j}\right) \\
& H_{2}=-\sum_{j=1}^{k} p_{2 j} \log _{2}\left(p_{2 j}\right) \\
& H_{k}=-\sum_{j=1}^{k} p_{k j} \log _{2}\left(p_{k j}\right)
\end{aligned}
$$

\section{Fuzzy Approach in Subjective Judgement Matrix Evaluation}

In this study, fuzzy number with symmetrical triangular membership function is used for evaluation of the impact strength of the alternatives in the hierarchy structure. A triangular membership function is limited by three parameters $\{\mathrm{x}, \mathrm{y}, \mathrm{z}\}$ as follows:

$$
\text { Triangle }(a ; x, y, z)=\left\{\begin{array}{cc}
0, & a \leq x . \\
\frac{a-x}{y-x}, & x \leq a \leq y . \\
\frac{z-a}{z-y}, & y \leq a \leq z . \\
0 & z \leq a .
\end{array}\right.
$$

A level threshold $(0<\alpha<1)$ of the fuzzy set is defined to avoid the complication and unreliable fuzzy classification. The symmetrical triangular fuzzy number with a level $\alpha$ interval confidence is determined as:

$$
M_{\alpha}=\left[x_{\alpha}, z_{\alpha}\right]=[(y-x) \alpha+x,(y-z) \alpha+z] \quad \forall \alpha \in[0,1]
$$


Table 4

Triangular Fuzzy Number Predefined Parameters

\begin{tabular}{ccccc}
\hline & Triangular Parameters & \multicolumn{2}{c}{ Triangular Fuzzy number with $\alpha$-level } \\
$(y-z) \alpha+z$
\end{tabular}

For positive fuzzy numbers with a level $\alpha$ interval of confidence, $\mathrm{M} \gamma$ and $\mathrm{N} \gamma$ the operations are:

$$
\begin{aligned}
& M_{\alpha}=\left[m_{\alpha}^{-}, m_{\alpha}^{+}\right], N_{\alpha}=\left[n_{\alpha}^{-}, n_{\alpha}^{+}\right] \quad \forall \gamma \in[0,1] \text { and } \forall m_{\alpha}^{-}, n_{\alpha}^{-}, m^{+}{ }_{\alpha}, n^{+}{ }_{\alpha} \in \mathfrak{R} \\
& M_{\alpha} / N_{\alpha}=\left[m_{\alpha}^{-}+n_{\alpha}^{-}, m^{+}{ }_{\alpha}+n^{+}{ }_{\alpha}\right] \\
& M_{\alpha} 0 N_{\alpha}=\left[m_{\alpha}^{-}-n_{\alpha}^{-}, m_{\alpha}^{+}-n^{+}{ }_{\alpha}\right] \\
& M_{\alpha} 1 N_{\alpha}=\left[m_{\alpha}^{-} \times n_{\alpha}^{-}, m^{+} \times n_{\alpha}^{+}\right] \\
& M_{\alpha} 2 N_{\alpha}=\left[m_{\alpha}^{-} / n_{\alpha}^{-}, m_{\alpha}^{+} / n_{\alpha}^{+}\right] .
\end{aligned}
$$

Two vectors are considered in Saaty's AHP for fuzzy judgment matrix (M) and weighting matrix (V). The $M$ is the fuzzy number's rank of each alternative which satisfies each criterion. Additionally, a total fuzzy judgment matrix $(T)$ is derived by the use of the interval arithmetic process and the entropy weight. The fuzzy judgment matrix $(M)$ for alternatives is shown by fuzzy linguistic terms as follows:

$$
M=\left[\begin{array}{cccc}
m_{11} & m_{12} & \ldots & m_{1 n} \\
m_{21} & m_{22} & \ldots & m_{2 n} \\
& & & \\
m_{n 1} & m_{n 2} & \ldots & m_{n n}
\end{array}\right]
$$

Each element ( $\left.\mathrm{m}_{\mathrm{ij}}\right)$ in the matrix $M$ shows the project experts' linguistic judgment of the strength impact of alternative $A_{i}(i=1,2, \ldots, \mathrm{n})$ with consideration to criterion $C_{j}(j=1,2, \ldots, \mathrm{n})$. For example, the alternative $\left(A_{i}\right)$ with consideration the $C_{a}$ linguistic term set is assigned as:

- $\{$ Extremely Expensive (EEx), Expensive (Ex), Above Average (AA), Average (A), Economic(Ec), Very Economic(VEc)\}

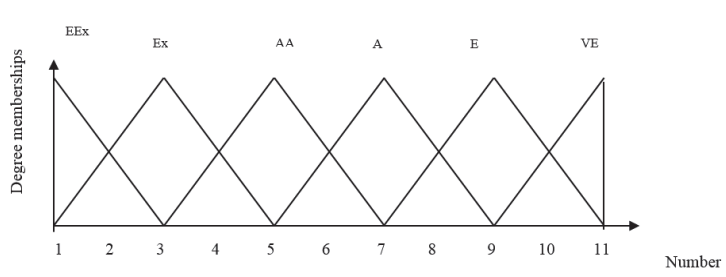

Fig. 3. Linguistic Terms $\boldsymbol{C}_{\boldsymbol{a}}$ in Fuzzy Judgment Matrix

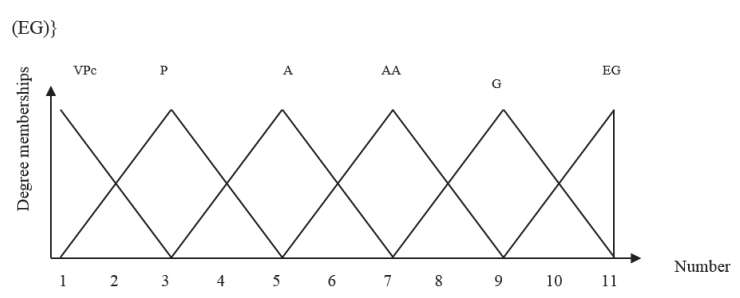

Fig. 4. Linguistic Terms $\boldsymbol{C}_{\boldsymbol{b}}$ in Fuzzy Judgment Matrix

Also, the alternative $\left(A_{i}\right)$ with consideration the $C_{b}$ linguistic term set is defined as:

- $\quad\{$ Very Poor (VP), Poor (P), Average (A), Above Average (AA), Good (G), Extremely Good (EG)\} For the weighting matrix, the evaluation of the strategy is represented by the linguistic term set as below:

- $\quad\{$ Insignificant (I), Weak (W), Fair (F), Above Fair (AF), Strong(S),Extremely Strong(ES) \} 


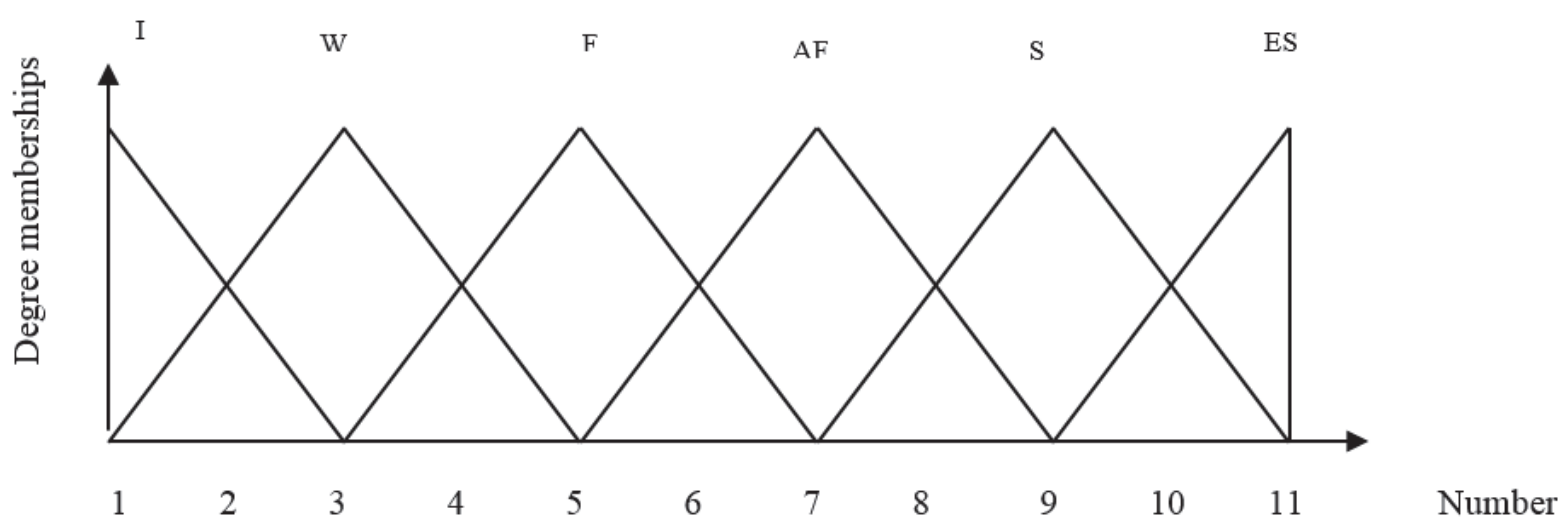

Fig. 5. Linguistic Terms in Weighting Matrix

Based on the above consideration, the project expert's judgments have compromised a fuzzy judgment matrix $(M)$ of four alternatives $\left(A_{1}, A_{2}, A_{3}\right.$ and $\left.A_{4}\right)$ which linked on criteria $\left(C_{a}, C_{b}\right)$ and symmetrical fuzzy numbers are used. The linguistic fuzzy judgment matrix $(M)$ is described as:

$$
\begin{aligned}
& C_{a} \quad C_{b} \\
& M=\begin{array}{l}
A_{1} \\
A_{2} \\
A_{3} \\
A_{4}
\end{array}\left[\begin{array}{cc}
A A & A A \\
E x & A A \\
E x & A \\
A & G
\end{array}\right]
\end{aligned}
$$

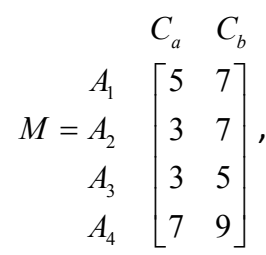

and the priority of the impact, the two criteria, cost-effectivity and overall performance outcome are shown by the weighting vector as follow:

$$
\begin{aligned}
& V=\left[\begin{array}{ll}
A F & S
\end{array}\right]=\left[\begin{array}{ll}
9 & 7
\end{array}\right] \\
& C_{a} \quad C_{b} \\
& M t=\begin{array}{l}
A_{1} \\
A_{2} \\
A_{3} \\
A_{4}
\end{array}\left[\begin{array}{cc}
9 \times 5 & 7 \times 7 \\
9 \times 3 & 7 \times 7 \\
9 \times 3 & 7 \times 5 \\
9 \times 7 & 7 \times 9
\end{array}\right]
\end{aligned}
$$

Fuzzy number calculation and the Shannon entropy rules are used for the entropy weight determination. From Eq. (2) and Table 2 and considering the $\alpha$-level (0.15) and defined optimism index, $\beta=0.5$ the total weighting vector is gained as below:

$$
\begin{aligned}
& \begin{array}{cccc}
C_{a} & C_{b} & C_{a} & C_{b}
\end{array}
\end{aligned}
$$

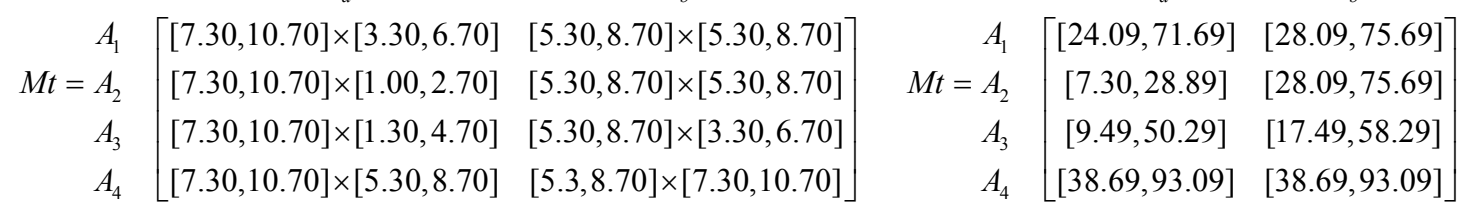

Determination of the moderate entropy weighting of the four alternatives $A_{1}, A_{2}, A_{3}$ and $A_{4}$ is evaluated with three different level of $\alpha,(0.15,0.50$ and 0.95$)$. It can be gained from Tables (3-5), we realize that the priority of the alternatives are in the order of $\mathrm{A}_{4}, \mathrm{~A}_{1}, \mathrm{~A}_{3}$ followed by $\mathrm{A}_{2}$ and regardless of the range of $\alpha$ value, and the result shown are consistent. 
Table 4

Moderate Entropy Weighting with $\alpha$-level $=0.15$

\begin{tabular}{|c|c|c|c|c|c|c|}
\hline \multirow[t]{2}{*}{ Alternative } & \multicolumn{2}{|c|}{$\begin{array}{l}\text { Linear convex } \\
\text { combination }\end{array}$} & \multicolumn{2}{|c|}{$-\sum p_{i} L O G 2\left(p_{i}\right)$} & \multirow[t]{2}{*}{$\begin{array}{c}\text { Entropy } \\
\text { weighting }\end{array}$} & \multirow[t]{2}{*}{ Priority } \\
\hline & $C_{a}$ & $C_{b}$ & $C_{a}$ & $C_{b}$ & & \\
\hline$A_{1}$ & 47.89 & 51.89 & 0.5083 & 0.4906 & 0.2619 & 2 \\
\hline$A_{2}$ & 18.10 & 51.89 & 0.5046 & 0.3200 & 0.2162 & 4 \\
\hline$A_{3}$ & 29.89 & 37.89 & 0.5209 & 0.4690 & 0.2600 & 3 \\
\hline$A_{4}$ & 65.89 & 65.89 & 0.5000 & 0.500 & 0.2622 & 1 \\
\hline
\end{tabular}

Table 5

Moderate Entropy Weighting with $\alpha$-level $=0.50$

\begin{tabular}{|c|c|c|c|c|c|c|}
\hline \multirow[t]{2}{*}{ Alternative } & \multicolumn{2}{|c|}{$\begin{array}{l}\text { Linear convex } \\
\text { combination }\end{array}$} & \multicolumn{2}{|c|}{$-\sum p_{i} L O G 2\left(p_{i}\right)$} & \multirow[t]{2}{*}{$\begin{array}{c}\text { Entropy } \\
\text { weighting }\end{array}$} & \multirow[t]{2}{*}{ Priority } \\
\hline & $C_{a}$ & $C_{b}$ & $C_{a}$ & $C_{b}$ & & \\
\hline$\overline{A_{1}}$ & 46.00 & 50.00 & 0.5086 & 0.4902 & 0.2667 & 2 \\
\hline$A_{2}$ & 14.00 & 50.00 & 0.4796 & 0.2782 & 0.2024 & 4 \\
\hline$A_{3}$ & 28.00 & 36.00 & 0.5218 & 0.4669 & 0.2640 & 3 \\
\hline $\boldsymbol{A}_{4}$ & 64.00 & 64.00 & 0.5000 & 0.5000 & 0.2670 & 1 \\
\hline
\end{tabular}

Table 6

Moderate Entropy Weighting with $\alpha$-level $=0.95$

\begin{tabular}{|c|c|c|c|c|c|c|}
\hline \multirow[t]{2}{*}{ Alternative } & \multicolumn{2}{|c|}{$\begin{array}{l}\text { Linear convex } \\
\text { combination }\end{array}$} & \multicolumn{2}{|c|}{$-\sum p_{i} L O G 2\left(p_{i}\right)$} & \multirow[t]{2}{*}{$\begin{array}{c}\text { Entropy } \\
\text { weighting }\end{array}$} & \multirow[t]{2}{*}{ Priority } \\
\hline & $\overline{C_{a}}$ & $C_{b}$ & $\overline{C_{a}}$ & $C_{b}$ & & \\
\hline$A_{1}$ & 45.01 & 49.01 & 0.5088 & 0.4899 & 0.2755 & 2 \\
\hline$A_{2}$ & 9.46 & 49.01 & 0.4351 & 0.2133 & 0.1761 & 4 \\
\hline$A_{3}$ & 27.01 & 35.01 & 0.5223 & 0.4657 & 0.2725 & 3 \\
\hline$A_{4}$ & 63.01 & 63.01 & 0.5000 & 0.5000 & 0.2759 & 1 \\
\hline
\end{tabular}

\section{Results and Discussion}

In this paper, based on the PMBOK, a questionnaire list was developed. The questionnaire was divided into 3 categories; inputs to scope control process, tools and techniques of scope control process and the outputs of scope control process. The scope creep causes were sorted in similar groups. The main causes of scope creep were Poor documentation, Poor change control, Poor information transformation and External changes.

Based on a literature review and the standard for portfolio management (PMI 2013) a complete conceptual model by considering strategic orientation were developed to manage scope change. This model can be used for future practical research on the effect of strategy on project management and its success. The model was based on Porter generic strategies; Cost leadership strategy, Differentiation strategy and Best-cost strategy. Finally the fuzzy AHP is used in selecting the best strategy to manage scope change. Fuzzy linguistic term was used to capture the fuzziness and subjective of importance upgrading alternatives selection in a multi criteria decision making in a project. The predefined fuzzy number with the certain confidence of level ( $\alpha$-cut-method) is able to avoid the conflict of the fuzzy ranking problem. The fuzzy approach in AHP has demonstrated the reliability of confidence in decision making since the different levels of optimism and $\alpha$-levels have no influence on the assessment 
outcome. In this case study ALTERNATIVE 4 (Control Cost) was selected strategy for managing scope changes in project.

\section{Conclusion}

During the project's lifecycle many changes take place, either positive or negative that should be controlled. In this paper, based on the PMBOK, the concept of project scope, scope change and scope creep has been presented. By analyzing the results of a questionnaire, the main causes of scope creep were introduced as Poor documentation, Poor change control, Poor information transformation, External changes. By considering this concept, in this paper, fuzzy AHP was used in selecting the best strategy to manage scope change in projects.

\section{Acknowledgement}

We would also like to show our gratitude to Mr. Fereydoon Honari (V.P. of Planning, MAPNA-MD2) for sharing his pearls of wisdom with us during the course of this research.

\section{References}

Alsudiri, T., Al-Karaghouli, W., \& Eldabi, T. (2013). Alignment of large project management process to business strategy: A review and conceptual framework. Journal of Enterprise Information Management, 26(5), 596-615.

Artto, K., Kujala, J., Dietrich, P., \& Martinsuo, M. (2008). What is project strategy?. International Journal of Project Management, 26(1), 4-12.

Cooke-Davies, T. (2002). The "real" success factors on projects. International journal of project management, 20(3), 185-190.

Crawford, L., \& Nahmias, A. H. (2010). Competencies for managing change. International journal of project management, 28(4), 405-412.

Crawford, L., Hobbs, J. B., \& Turner, J. R. (2006). Aligning capability with strategy: Categorizing projects to do the right projects and to do them right. Project Management Journal, 37(2).

De Reyck, B., Grushka-Cockayne, Y., Lockett, M., Calderini, S. R., Moura, M., \& Sloper, A. (2005). The impact of project portfolio management on information technology projects. International Journal of Project Management, 23(7), 524-537.

Duggal, J. S. (2010). Next Level Up: How Do You Measure Project Success? Rethinking the Triple Constraint. Project Management Institute Community Post.

Eriksson, P. E. (2013). Exploration and exploitation in project-based organizations: Development and diffusion of knowledge at different organizational levels in construction companies. International Journal of Project Management, 31(3), 333-341.

Fan, Y., Miyagi, H., \& Yamashita, K. (1998, October). Decision-making problem with the vague criteria based on the fuzzy relation equation. In Systems, Man, and Cybernetics, 1998. 1998 IEEE International Conference on (Vol. 3, pp. 2574-2578). IEEE.

Guide, A. (2013). Project Management Body of Knowledge (PMBOK® GUIDE). In Project Management Institute.

Hauc, A., \& Kovač, J. (2000). Project management in strategy implementation-experiences in Slovenia. International Journal of Project Management, 18(1), 61-67.

Kerzner, H. R. (2013). Project management: a systems approach to planning, scheduling, and controlling. John Wiley \& Sons.

Lehtonen, P., \& Martinsuo, M. (2009). Integrating the change program with the parent organization. International Journal of Project Management, 27(2), 154-165.

MAPNA Integrated management system procedures

Meredith, J. R., \& Mantel Jr, S. J. (2011). Project management: a managerial approach. John Wiley \& Sons. 
Meskendahl, S. (2010). The influence of business strategy on project portfolio management and its success - a conceptual framework. International Journal of Project Management, 28(8), 807817.Miller, D. (2001). Successful change leaders: what makes them? What do they do that is different?. Journal of Change Management, 2(4), 359-368.

Mon, D. L., Cheng, C. H., \& Lin, J. C. (1994). Evaluating weapon system using fuzzy analytic hierarchy process based on entropy weight. Fuzzy sets and systems, 62(2), 127-134.

Morris, P., \& Jamieson, A. (2005). Moving from corporate strategy to project strategy. Project Management Journal, 36(4), 5-18.

Patanakul, P., \& Shenhar, A. J. (2012). What project strategy really is: The fundamental building block in strategic project management. Project Management Journal, 43(1), 4-20.

Porter, M. E. (1980). Competitiw strategy.

Rowe, G., \& Wright, G. (1999). The Delphi technique as a forecasting tool: issues and analysis. International journal of forecasting, 15(4), 353-375.

Shenhar, A. J., Milosevic, D., \& Dvir, D. (2000). Linking project management to business strategy. Project Management Institute.

Shi, Q. (2011). Rethinking the implementation of project management: A Value Adding Path Map approach. International Journal of Project Management, 29 (3), 295-302.

Srivannaboon, S. A. B. I. N., \& Milosevic, D. Z. (2006). A theoretical framework for aligning project management with business strategy. Project Management Journal, 37(3), 98-110.

Srivannaboon, S., \& Milosevic, D. Z. (2006). A two-way influence between business strategy and project management. International journal of project management, 24(6), 493-505.

Stummer, M., \& Zuchi, D. (2010). Developing roles in change processes-A case study from a public sector organisation. International Journal of Project Management, 28(4), 384-394.

Saaty, T. L. (1990). How to make a decision: the analytic hierarchy process. European journal of operational research, 48(1), 9-26.

Sun, M., \& Meng, X. (2009). Taxonomy for change causes and effects in construction projects. International Journal of Project Management, 27(6), 560-572.

Thomas, J., \& Mengel, T. (2008). Preparing project managers to deal with complexity-Advanced project management education. International Journal of Project Management, 26(3), 304-315.

Wheelen, T. L., \& David, J. (2002). Hunger. Strategic Management and Business Policy.

Yeh, C. H., \& Deng, H. (1997, October). An algorithm for fuzzy multi-criteria decision making. In Intelligent Processing Systems, 1997. ICIPS'97. 1997 IEEE International Conference on (Vol. 2, pp. 1564-1568). IEEE.

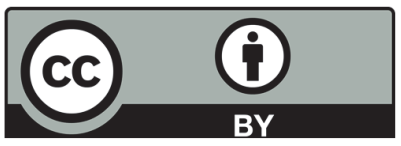

(C) 2017 by the authors; licensee Growing Science, Canada. This is an open access article distributed under the terms and conditions of the Creative Commons Attribution (CC-BY) license (http://creativecommons.org/licenses/by/4.0/). 